\title{
Porokeratosis of Mibelli
}

\author{
Constanza Riquelme-Mc Loughlin ${ }^{1}$, Sebastian Podlipnik ${ }^{1,2}$
}

1 Department of Dermatology, Hospital Clínic Barcelona, Universitat de Barcelona, Spain

2 Institut d'Investigacions Biomediques August Pi I Sunyer (IDIBAPS), Barcelona, Spain

Key words: porokeratosis, Mibelli, dermoscopy, cornoid lamella

Citation: Riquelme-Mc Loughlin C, Podlipnik S. Porokeratosis of Mibelli. Dermatol Pract Concept. 2020;10(4):e2020112.

DOI: https://doi.org/10.5826/dpc.1004a112

Accepted: May 27, 2020; Published: October 26, 2020

Copyright: $\odot 2020$ Riquele McLoughlin and Podlipnik. This is an open-access article distributed under the terms of the Creative Commons Attribution License (CC-BY-NC-4.0), which permits unrestricted noncommercial use, distribution, and reproduction in any medium, provided the original author and source are credited.

Funding: None.

Competing interests: The authors have no conflicts of interest to disclose.

Authorship: All authors have contributed significantly to this publication.

Corresponding author: Sebastian Podlipnik, MD, Department of Dermatology, Hospital Clínic Barcelona, Universitat de Barcelona, Villarroel 170, 08036, Barcelona, Spain. Email: spodlipnik@gmail.com

\section{Case Presentation}

A 52-year-old man with no past medical history presented with an asymptomatic annular atrophic patch on the distal portion of the fourth toe of 2 years' duration (Figure 1B). The lesion began as a small keratotic papule that gradually enlarged centrifugally. He had received multiple treatments including cryotherapy, topical corticosteroids, antifungals, and antibiotics without improvement. Dermoscopic examination revealed a scaly atrophic erythematous central area with a sharply demarcated peripheral hyperkeratotic structure (Figure 1A). A skin biopsy of the edge of the lesion revealed a cornoid lamella with a column of parakeratotic cells extending from an invagination of the epidermis with absence of granular layer (Figure 1C). The clinicopathologic correlation was consistent with porokeratosis of Mibelli.
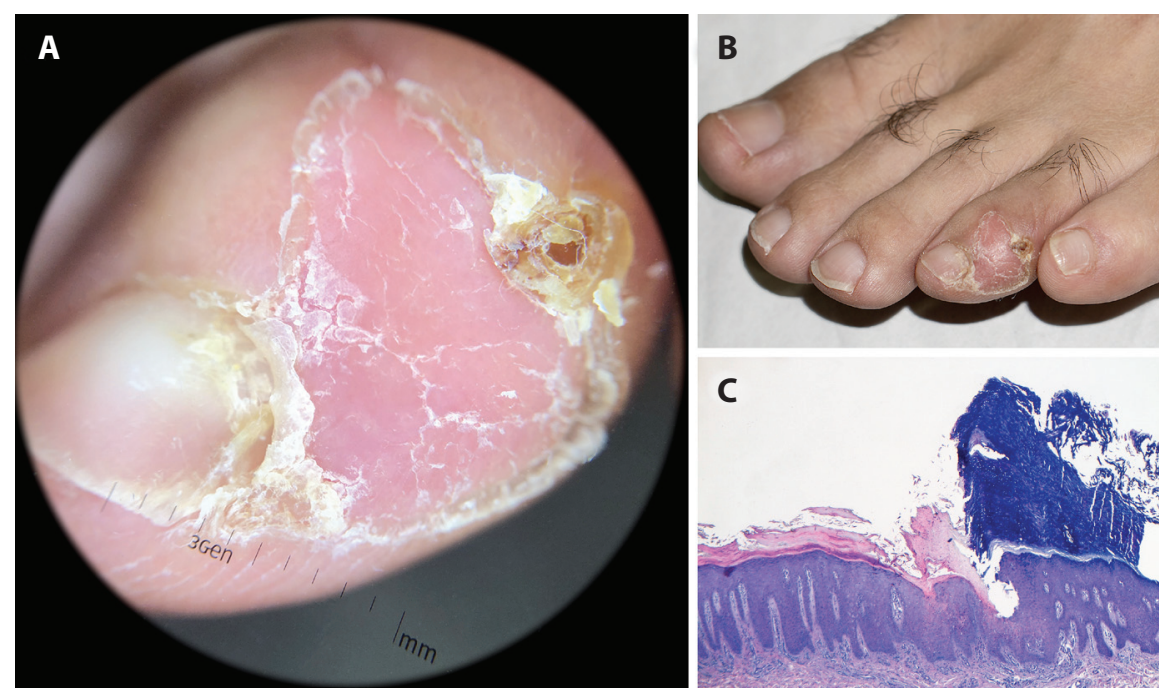

Figure 1. (A) Polarized dermoscopy (DermLite II PROHR; magnification $\times 10)$ reveals a scaly atrophic erythematous central area, with a sharply demarcated peripheral hyperkeratotic structure (cornoid lamella). (B) Unilateral annular patch on the distal portion of the fourth toe of the left foot. (C) Punch biopsy of the edge of the lesion reveals a cornoid lamella with a column of parakeratotic cells extending from an invagination of the epidermis with absence of granular layer; H\&E, magnification $\times 40$. 


\section{Teaching Point}

Porokeratosis can be mistaken with cutaneous squamous cell carcinoma in situ [1], tinea corporis, and circumscribed plantar hypokeratosis, among other annular lesions. Dermoscopy is a useful tool that improves diagnostic accuracy and allows visualization of the cornoid lamella [2].

\section{References}

1. Sousa Herênio A, de Morais Cavalcanti SM, Rodrigues de França E, Marques Maranhão C, Barbosa de Alencar ER. Porokeratosis simulating Bowen's disease on dermoscopy. An Bras Dermatol. 2016;91(5 supplement 1):119-121. DOI: 10.1590/abd18064841.20164479. PMID: 28300916.

2. Navarrete-Dechent C, Uribe P, Marghoob A. Ink-enhanced dermoscopy is a useful tool to differentiate acquired solitary plaque porokeratosis from other scaly lesions. J Am Acad Dermatol. 2019;80(6):e137-138. DOI: 10.1016/j.jaad.2017.11.052. PMID: 29221722. 